\title{
Hackathon como Modelo de Aprendizagem Ativa: Estudo de Caso de uma Instituição de Ensino Superior do Noroeste Gaúcho
}

\section{Hackathon as an Active Learning Model: Case Study of a Higher Education Institution in the Northwest of Rio Grande do Sul}

\author{
Nedisson Luis Gessi 1*, Co-autor 1: Denise Felber Chaves, Co-autor 2: Marilei de Fátima \\ Kovatli, Co-autor 3: Bruna Knob Pinto, Co-autor 4: Juliane Colpo, Co-autor 5: Antonio \\ Lausmann Ternes, Co-autor 6: Elisiane Bisognin, Co-autor 7: Paulo Roberto Mix
}

\begin{abstract}
RESUMO
O artigo investiga a importância do Hackathon como modelo de aprendizagem ativa e promover a reflexão de novas abordagens pedagógicas através de um estudo de caso em uma instituição de ensino superior no noroeste gaúcho. O método de abordagem foi qualitativo com enfoque teórico-crítico, analisando a aplicabilidade da atividade bem como de que forma ela contribui para o processo de construção do conhecimento dos acadêmicos. Considera-se que a aprendizagem ocorre por meio da interação professoraluno e que o papel do professor é de pesquisador e mediador. O questionário aplicado aos acadêmicos aponta para aspectos da aprendizagem autônoma e cooperativa, bem como a atual desfragmentação espaçotemporal do aprender. Conclui-se que os Hackathons educativos são uma oportunidade de inovação que permitem impactos nas dimensões cognitivas, sociais e comportamentais, promovendo práticas docentes inovadoras.
\end{abstract}

Palavras-chave: Hackathon; aprendizagem ativa; inovação; abordagem pedagógica.

\begin{abstract}
The article investigates the importance of Hackathon as an active learning model and promotes reflection on new pedagogical approaches through a case study in a higher education institution in northwestern Rio Grande do Sul. The approach method was qualitative with a theoretical-critical focus, analyzing the applicability of the activity as well as how it contributes to the process of construction of knowledge among students. It is considered that learning takes place through teacher-student interaction and that the teacher's role is that of a researcher and mediator. The questionnaire applied to students points to aspects of autonomous and cooperative learning, as well as the current spatiotemporal defragmentation of learning. It is concluded that educational hackathons are an opportunity for innovation that allow impacts on cognitive, social and behavioral dimensions, promoting innovative teaching practices.
\end{abstract}

Keywords: Hackathon; active learning; innovation; pedagogical approach.

${ }^{1}$ Faculdades Integradas Machado de Assis. *E-mail: nedisson@fema.com.br; denisef@fema.com.br; marilei_gti@fema.com.br; brunaknob@fema.com.br; jcolpo@fema.com.br; faculdades@fema.com.br; elisiane.2013rh@gmail.com; paulomix@fema.com.br. 


\section{INTRODUÇÃO}

A importância do protagonismo do aluno no processo de construção do conhecimento está cada vez mais evidente. Para isso, é fundamental que instituições de ensino invistam em metodologias ativas e aprendizagem personalizada que considere as diversas dimensões e particularidades dos alunos.

Diante disso, esse artigo tem como objetivo investigar a importância do Hackathon como modelo de aprendizagem ativa e promover a reflexão de novas abordagens pedagógicas através de um estudo de caso em uma instituição de ensino superior no noroeste gaúcho.

O Hackathon é um método de aprendizagem que promove a interdisciplinaridade através da proposição de casos e desafios permitindo a construção de soluções de forma coletiva. Ele viabiliza o usos de uma metodologia de estudo voltada a construção do conhecimento valorizando a ação entre alunos e tornando o professor mediador do processo.

O estudo de caso em especifico, desenvolvido em uma instituição de ensino do interior gaúcho, foi realizada de forma online, quebrando barreiras temporais e espaciais no momento da aprendizagem. O Hackathon realizado buscou trazer a mente dos professores envolvidos seu papel como pesquisadores educacionais e mediadores do processo de ensino-aprendizagem.

Para a construção do artigo, iniciou-se pela investigação teórica da relação entre Escola e a Sociedade, Estudantes e Professores da Era Digital e Hackathon como instrumento de inovação. Em seguida, a apresentação da atividade desenvolvida com os acadêmicos da Instituição de Ensino em estudo e a pesquisa realizada. Posteriormente, de forma sucinta, evidencia-se alguns pontos de maior relevância no uso de metodologias ativas nos ambientes de ensino.

\section{Relação entre Escola e a Sociedade}

O ambiente educacional não pode estar à parte do mundo real, que hoje é digitalizado e interativo. Questiona-se a sua eficácia, a sua função, e, principalmente, a sua inserção na sociedade atual. É comum se apontar que a cultura evoluiu e os sistemas 
educacionais ficaram no passado, especialmente no uso de novas tecnologias e metodologias. Segundo Goodson (1999),

[...] precisamos avançar, com firmeza e análise para longe dos modelos de administração técnicos, racionais ou científicos; para longe do 'jogo de interesses'. Acima de tudo, precisamos abandonar o enfoque único posto sobre o currículo como prescrição. Isto significa que devemos adotar plenamente o conceito de currículo como construção social, primeiramente em nível da própria prescrição, mas depois também em nível de processo e prática. (GOODSON, 1999, p. 67).

Nessa nova sociedade, cada vez mais conectada, a própria escola pode ser vista como uma tecnologia educacional, uma vez que ela é uma construção social humana. Segundo Dewey (2007) a escola, baseada no princípio de "preparação para a vida" se tornava um ambiente artificial, uma falsificação da vida, uma vivência que não irá se repetir em nenhum outro momento dela. A escola deve ser a própria vida, estando o mais próximo possível da cultura em que vivem os alunos. Neste princípio, diante de nossa cultura digital, uma escola que não usa as tecnologias e metodologias ativas falsifica o próprio processo educacional.

Observa-se que o desenvolvimento tecnológico e informacional avança tão rápido que toma uma forma autônoma, incorrendo em dificuldades de acompanhá-lo. Nossa sociedade, conhecida como Sociedade da Informação ou do Conhecimento se encontra em processo de formação e expansão em meio a um desenvolvimento tecnológico e informacional sem precedentes, em que a informação e o conhecimento produzidos impactam na sociedade. Conforme Strieder (2008)

[...] a escola, além de se preocupar com novas tecnologias e descobertas, deve se preocupar com o impacto que essas novas tecnologias podem trazer ao serem lançadas em nosso ambiente. Devemos nos preocupar com a formação intelectual e social de todos; assim podemos contribuir para uma melhor convivência em nossa sociedade (STRIEDER, 2008, p. 28).

No entanto, temos observado que os artefatos tecnológicos e as metodologias ativas crescem sem controle e a própria sociedade tem dificuldade em acompanhá-los. Nesse contexto entra o papel da educação que abandona os modelos rígidos e se torna 
flexível utilizando as novas tecnologias e formas de aprendizagem a fim de preparar os alunos para que eles estejam totalmente inseridos na nova sociedade.

Para Freire (1987, p. 80) “a educação problematizadora de caráter autenticamente reflexivo, implica um constante ato de desvelamento da realidade, [...] busca a emersão das consciências, de que resulte sua inserção crítica na realidade”. A aplicação dessas novas tecnologias devem ser contextualizadas em um projeto pedagógico mais abrangente que atenda essa percepção.

Hoje, diante dessa nova realidade temos os alunos chamados "nativos digitais", que é todo aquele que nasceu e cresceu com as novas tecnologias. Segundo Alves (2005),

É esse ambiente tecnológico que se configura como locus de onde surgem os nativos digitais, ou seja, jovens que navegam em vários sites, falam ao celular, comunicam-se em chats, ouvem música, etc, tudo isso simultaneamente. Esses jovens e crianças estabelecem uma relação dialética com os elementos midiáticos, interagindo com seus diversos estilos: impressos, imagéticos, digitais, sonoros. Tal geração utiliza um período de seu tempo imersa no computador, sempre mediatizados por artefatos tecnológicos. Os nativos digitais demonstram alto nível de interatividade com as novas mídias. (ALVES, 2005, p. 38)

Os nativos digitais, que representam a grande maioria de alunos presentes nas salas de aula, não mais reconhecem a sua realidade na escola tradicional. A introdução de novas tecnologias na sociedade leva a uma preocupação mundial com relação à urgência da sua aplicação na educação, para assim aproveitar os seus benefícios e evitar que se tornem mais um fator de diferenciação social e econômica. O uso das tecnologias na educação e metodologias ativas aponta a necessidade de uma maior flexibilidade dos sistemas educacionais para atender às próximas transformações sociais. Como destacado por Fourez (2003),

A compreensão desta implicação do social na construção das tecnologias torna possível um estudo crítico destas, como o fazem os trabalhos de avaliação social das tecnologias. Uma formação para a negociação com as tecnologias deve tornar os alunos capazes de analisar os efeitos organizacionais de uma tecnologia. (FOUREZ, 2003, p.10)

O uso das tecnologias tem chamado a atenção de governos, empresas e sociedade em geral, pois é uma grande potência repleta de desafios. O estudo da história da educação 
e dos currículos escolares aponta para a necessidade de adaptação de todo o sistema educacional, sem a negação de si mesmo e de cada identidade nacional. Surge então a urgência de uma equidade no uso de novas tecnologias na educação e metodologias ativas. Esse contexto lembra também sobre a conscientização da importância da formação continuada de professores para o uso de novas tecnologias e metodologias.

Para Freire (1987), a consciência relaciona-se ao olhar mais crítico possível sobre a realidade, para que seja possível conhecê-la e agir sobre ela. Dessa forma, o autor defende que a educação precisa estimular a reflexão sobre a realidade, contribuindo, assim, para que a sociedade participe de forma consciente da construção de sua própria história.

A verdade é que as salas de aula, a muito tempo, vem sendo apoiadas pelas inovações, com aulas expositivas, atividades práticas e pesquisas que necessitam do suporte de tecnologias, mesmo que estas sejam apenas quadro-negro e livros. Assim, percebe-se que a escola sempre foi assimilando os novos suportes que se tornavam disponíveis para a potencialização da ação didática e o professor esteve em desafio constante para manter-se atualizado e acompanhar o ritmo de desenvolvimento desses novos conhecimentos e informações.

\section{Estudantes e Professores da Era Digital}

A medida que as tecnologias evoluem e ocorrem mudanças na forma de comunicação e interação entre as pessoas, também ocorrem mudanças na forma com que as novas gerações aprendem e consequentemente, como os professores trabalham com esses alunos que cresceram com a tecnologia ao seu lado.

Os educadores precisam adaptar suas práticas de ensino "em uma sociedade em que lidar com o conhecimento é uma questão de negociação e criatividade e em que aprender é uma atividade para a vida toda." (VEEN; VRAKKING, 2009, p. 11). Convém, no entanto, lembrar que foi necessário muito tempo para a educação chegar ao ponto em que está hoje e nem todos os hábitos estabelecidos são ruins.

Veen e Vrakking (2009) chamam a nova geração de estudantes, que cresceram em meio às múltiplas tecnologias, de Homo zappiens. O uso de recursos tecnológicos permitiu às crianças nascidas nesse século o domínio do fluxo de informações, o uso de 
comunidades virtuais e reais, comunicação e colaboração em rede, de acordo com as necessidades que surgirem. Segundo Veen e Vrakking (2009),

O Homo Zappiens é um processador ativo de informação, resolve problemas de maneira muito hábil, usando estratégias de jogo, e sabe se comunicar muito bem. Sua relação com a escola mudou profundamente, já que as crianças e os adolescentes Homo zappins consideram a escola apenas um dos pontos de interesse em suas vidas. [...] Mas o Homo zappiens quer estar no controle daquilo com que se envolve e não tem paciência para ouvir um professor explicar o mundo de acordo com suas próprias convicções. Na verdade, o Homo zappiens é digital e a escola analógica. (VEEN; VRAKKING, 2009, p. 12)

Para Veen e Vrakking (2009) os estudantes da era digital aprendem por meio de brincadeiras, atividades de investigação e descobertas relacionadas ao ato de brincar.

Sua aprendizagem começa tão logo ele jogue no computador e a aprendizagem logo se torna uma atividade coletiva, já que os problemas serão resolvidos de maneira colaborativa e criativa, em uma comunidade global. Os jogos de computador desafiam o Homo zappiens a encontrar estratégias adequadas para resolver problemas, a definir e categorizar problemas e uma variedade de outras habilidades metacognitivas na aprendizagem. (VEEN; VRAKKING, 2009, p. 12)

Ao contrário da educação tradicional, onde a aprendizagem relacionava-se ao conteúdo disciplinar, hoje o conhecimento está em constante mudança dentro de um domínio específico, onde o sujeito busca a sua construção a partir de informações, dando significado a elas. Conforme Veen e Vrakking (2009),

Podemos chegar à conclusão que as crianças de hoje de fato possuem estratégias e habilidades de aprendizagem que são cruciais para dar significado às informações, e que estas habilidades e estratégias são vitais para a aprendizagem futura em uma economia intensamente baseada no conhecimento. (VEEN; VRAKKING, 2009, p. 13)

Essa geração entra em conflito com a escola tradicional que busca transferir conhecimento da mesma forma que ocorre há 100 anos, em uma estrutura econômica e sociedade em constante mudança. Segundo Veen e Vrakking (2009) a escola precisa, em 
primeiro lugar, reconhecer as habilidades e estratégias que o Homo zappiens desenvolveu e buscar respostas para as necessidades desses novos alunos.

Conforme Veen e Vrakking (2009) diante dessa nova geração que oferece a oportunidade para tornar a educação uma profissão motivadora e apaixonante,

[...] os professores tornam-se orientadores que oferecem um apoio especializado às crianças, que, por sua vez, aprendem de maneira mais independente sobre questões e problemas da vida real. A sociedade do futuro exige que seus cidadãos sejam capazes de lidar com a complexidade, tanto na vida particular quanto na profissional. (VEEN; VRAKKING, 2009, p. 14)

A sociedade atual está em constante mutação e evolução. Logo, será necessário formar cidadãos capazes de lidar com problemas complexos e encontrar soluções inesperadas. Da mesma forma, "aquisição de conteúdo deixará de ser a meta principal da educação, que dará mais ênfase ao que é significativo e relevante". (VEEN; VRAKKING, 2009, p. 14). O principal objetivo do ambiente escolar será o de facilitar a aprendizagem para alunos que vivem e trabalham em organizações de intenso fluxo de conhecimento e precisam se adaptar com condições e situações em constante mudança.

Segundo Veen e Vrakking (2009, p. 27) “os alunos de hoje demandam novas abordagens e métodos de ensino para que se consiga manter a atenção e a motivação na escola". A preocupação com essas crianças, adolescentes e jovens começa em casa quando os pais percebem que estes preferem passar o tempo em frente ao computador ou televisão trazendo como consequência o empobrecimento do convívio social.

Esse comportamento é consequência das mudanças socioeconômicas que ocorreram com o uso da tecnologia digital, considerando que todos sofremos a influência do contexto social no qual crescemos. Logo, o que os alunos fazem e pensam é resultado da interação com o mundo externo.

Veen e Vrakking (2009) afirmam que,

Os primeiros seres digitais, cresceram em um mundo onde a informação e a comunicação estão disponíveis a quase todas as pessoas e podem ser usadas de maneira ativa. As crianças hoje passam horas de seu dia assistindo à televisão, jogando no computador e conversando nas salas de bate-papo. Ao fazê-lo, elas processam quantidades enormes de informação por meio de uma grande variedade de tecnologias e meios. Elas comunicam com amigos e outras pessoas de maneira muito mais intensa do 
que as gerações anteriores, usando a televisão, o MSN, os telefones celulares, os IPods, os blogs, os Wikis, as salas de batepapo na internet, os jogos e outras plataformas de comunicação. Usam esses recursos e essas plataformas em redes técnicas globais, tendo o mundo como quadro de referência. (VEEN; VRAKKING, 2009, p. 29)

O uso dessas tecnologias influencia o modo de pensar e agir do chamado Homo zappiens. Para essa geração é possível encontrar as informações de forma muito fácil através da internet atuando em uma cultura cibernética global com base na multimídia. A importância do domínio dessa tecnologia está no fato de que esses alunos aprendem desde cedo a ter acesso e controle a uma ampla variedade de fluxos de informação e comunicação.

O uso de diferentes tecnologias e metodologias de aprendizagem pode auxiliar no desenvolvimento de novos esquemas cognitivos que potencializam os processos de aquisição e consolidação de conhecimentos em uma sociedade onde os recursos tecnológicos surgem e se modificam a uma velocidade impressionante. Neste contexto é necessário usar instrumentos de inovação também no ambiente escolar.

\section{Hackathon como instrumento de inovação}

Pode-se dizer que Hackathons são oportunidades de desenvolver e transformar ideias em soluções para a sociedade por meio da tecnologia e inovação.

Segundo Raimundo, o termo Hackathon origina-se das palavras inglesas "hacking" e "marathon" usada pela primeira fez por Niels Provos, em 1999, quando realizou o primeiro Hackathon no cenário corporativo. $\mathrm{O}$ evento tornou-se reconhecido pela capacidade de resolução de problemas de forma criativa. (RAIMUNDO, 2020).

Nesse tipo de maratona os participantes são divididos em grupos e colaboram intensivamente por um curto período de tempo, que costuma variar entre 24 e $48 \mathrm{~h}$. Juntos, projetam e constroem protótipos testáveis para a resolução de um determinado problema que atinge uma empresa, um grupo de pessoas, ou a sociedade como um todo.

Para as empresas, segundo Oliveira e Lott, os eventos são benéficos em geração de ideias, identificação de talentos em potencial e estímulo ao uso inovador de seus produtos ou serviços (OLIVEIRA, LOTT, 2019). Na maioria dos casos é oferecida uma premiação que visa estimular a competição e a participação nos envolvidos. 
Oliveira e Lott afirmam que, conforme a empresa, os hackathons podem ser adaptados para acelerar o processo de transformação digital ou possibilitar uma entrega de inovações disruptivas no ritmo acelerado das startups, uma vez que "a estrutura descontraída encoraja os participantes a inovar e cria um ambiente favorável à inovação, gerenciando o fracasso necessário para o seu surgimento". (OLIVEIRA, LOTT, 2019).

Um Hackathon no ambiente educacional é algo inovador. Em um formato online quebra barreiras temporais e espaciais nos diferentes momentos da aprendizagem. Raimundo destaca que o evento é conhecido pela "capacidade criativa e empreendedora do processo ao qual os participantes são submetidos uma vez que a resolução rápida de problemas traz produtos que resolvem situações reais, muitas vezes complexas, de modo novo e objetivo". (RAIMUNDO, 2020). Por essas mesmas razões, a prática do Hackathon pode ser usada, de forma bem sucedida, como abordagem pedagógica, uma vez que resulta em "aprendizagem significativa de conceitos e habilidades na prática através de desafios contextualizados"(RAIMUNDO, 2020).

Há uma nova visão de que o professor deve atuar como pesquisador em sala de aula, experimentando e investindo em novas abordagens pedagógicas que instiguem nos estudantes a vontade de aprender.

O ambiente escolar busca inovação que surge da junção entre teoria e prática. Esses dois elementos combinados desenvolvem nos estudantes a capacidade de atuar com foco na resolução de problemas de maneira empreendedora. Para Raimundo "o grande desafio é fazer com que, em curto período de tempo, os alunos construam soluções eficientes e embasadas em dados ora levantados por eles através de validações de campo, ora buscados na teoria e conhecimentos científicos já consagrados".(RAIMUNDO, 2020).

Para que isso ocorra o setor pedagógico por trabalhar através de estratégias de Aprendizagem Baseada em Projetos (PBL - Project Based Learning) em que o projeto atua como disparador para a aprendizagem. Ocorre então uma inversão do método tradicional em que ocorrem as aulas expositivas para posteriormente pensar em sua aplicação prática. Ao usar PBL através de um desafio bem elaborado, a aquisição de conhecimento ocorre por intermédio do andamento da elaboração da proposta. $\mathrm{O}$ Hackathon "se caracteriza pelo curto tempo de execução, pela elaboração de soluções aos problemas do mundo e pela especial ênfase ao uso da tecnologia e do empreendedorismo como parte orgânica da solução apresentada no produto final." (RAIMUNDO, 2020). 
O processo inovador é parte do que se propõe como tecnologia, sendo que recursos simples podem ser usados como alternativa para resolução de problemas, uma vez que os elementos socioculturais devem ser considerados durante o processo de busca por soluções. Dessa forma, conforme destaca Raimundo, os desafiados podem desenvolver diferentes habilidades, além de consolidar o conhecimento formal e multidisciplinar, através da busca por soluções assertivas e escaláveis em diferentes áreas do conhecimento. (RAIMUNDO, 2020).

O evento também está diretamente ligada o empreendedorismo, uma vez que a prática do Hackathon, segundo Raimundo visa "garantir que os estudantes consigam dominar seus processos e favorecer que sejam capazes de levar adiante suas intenções, transformando ideias em ações objetivas e planejadas nas diversas áreas e situações". (RAIMUNDO, 2020).

O Hackathon ocorre em três fases: ideação, prototipação e construção de pitches. Raimundo enfatiza que é esperado que os estudantes possam aprender técnicas para expressar suas ideias e mapeamento as oportunidades "através de estratégias de design thinking, exploração e pesquisa, sendo capazes de prototipar ideias para que dar suporte à solução de um problema, e testá-las, finalizando na criação de um discurso oral capaz de persuadir a audiência". (RAIMUNDO, 2020).

Desta forma, a equipe proponente da atividade deve fornecer ferramentas para a instrumentalização dos projetos, tanto do ponto de vista técnico quanto processual. A comunidade escolar deve fornecer abertura para a criatividade dando autonomia ao estudante que desenvolverá um protótipo funcional, testado e validado no campo teóricoprático, e apresentado publicamente, o que, segundo Raimundo, refletirá na "satisfação da cocriação criativa será o gatilho para aprendizagem ativa e com significado, portanto significativa". (RAIMUNDO, 2020).

Considerando-se que o ambiente educacional deve preocupar-se com a formação integral do indivíduo em todas as suas dimensões, o uso de diferentes abordagens e metodologias, em especial o Hackathon, propicia não só o conhecimento teórico necessário ao estudante, como também o desenvolvimento da dimensão humana. 
O Hackathon Health é uma maratona que buscou reunir estudantes do Bacharelado em Enfermagem para desenvolverem soluções inovadoras para a área da saúde. O evento organizado através da IATI - Incubadora Acadêmica de Tecnologia e Inovação, ocorreu nos dias 25 de junho e 02 de julho, de forma online através da Plataforma da FEMA.

Na primeira noite foi apresentado um desafio da área da saúde: baixa adesão ao aleitamento materno, apresentado por duas profissionais da área da saúde de Santa Rosa $-\mathrm{RS}$.

Os acadêmicos, reunidos em grupos, trabalharam em soluções inovadoras. Empresas parceiras da IATI foram convidadas para mentorar as equipes: CEO da empresa Atendare startup; CEO da empresa IUBI; CEO da empresa Coan Gestão+Inovação; fundadora da ABA Academy; e CEO da empresa Leaper.

$\mathrm{Na}$ metodologia proposta, divididos em seis equipes, os acadêmicos deveriam cumprir determinadas etapas para vencer a competição utilizando as ferramentas: Cartão de teste - problema e solução; Cartão de Aprendizado - problema e solução; Lean Canvas; Ferramenta VRIO; Ferramenta PITCH Puma.

$\mathrm{Na}$ primeira noite de maratona as equipes deveriam cumprir as etapas: ideia(hipótese), definição do problema, validação do problema, criação da solução. Já na segunda noite, as tarefas eram criação do MVP (Mínimo Produto Viável) e PITCH. As soluções foram apresentadas através de um Pitch e avaliadas por mentores, profissionais da área da saúde e organizadores do evento. Entre elas destacaram-se ideias de aplicativos, plataformas, assistentes virtuais, centro de capacitação, entre outras.

A equipe vencedora propôs o uso de um aplicativo preocupando-se com todas as etapas, conseguindo ao final da segunda noite apresentar um MVP (Mínimo Produto Viável) completo.

A banca de especialistas, formados por diferentes área de atuação, avaliaram aspectos como valor econômico ou social e compatibilidade entre a proposta e o problema a ser sanado. A comissão organizadora destacou que todas as ideias propostas atenderam ao objetivo de enfrentamento para aumentar o aleitamento materno exclusivo até o sexto mês de vida do bebê e são passíveis de serem implantadas. 
Para avaliar a aprendizagem e percepção dos acadêmicos foi realizada uma pesquisa com os trinta e cinco participantes, com dez questões fechadas e uma questão aberta, cujo resultado está demostrado na sequência.

A primeira questão buscou avaliar como a atividade foi considerada, o que está demostrado na Figura 1:

Figura 01- aproveitamento da atividade

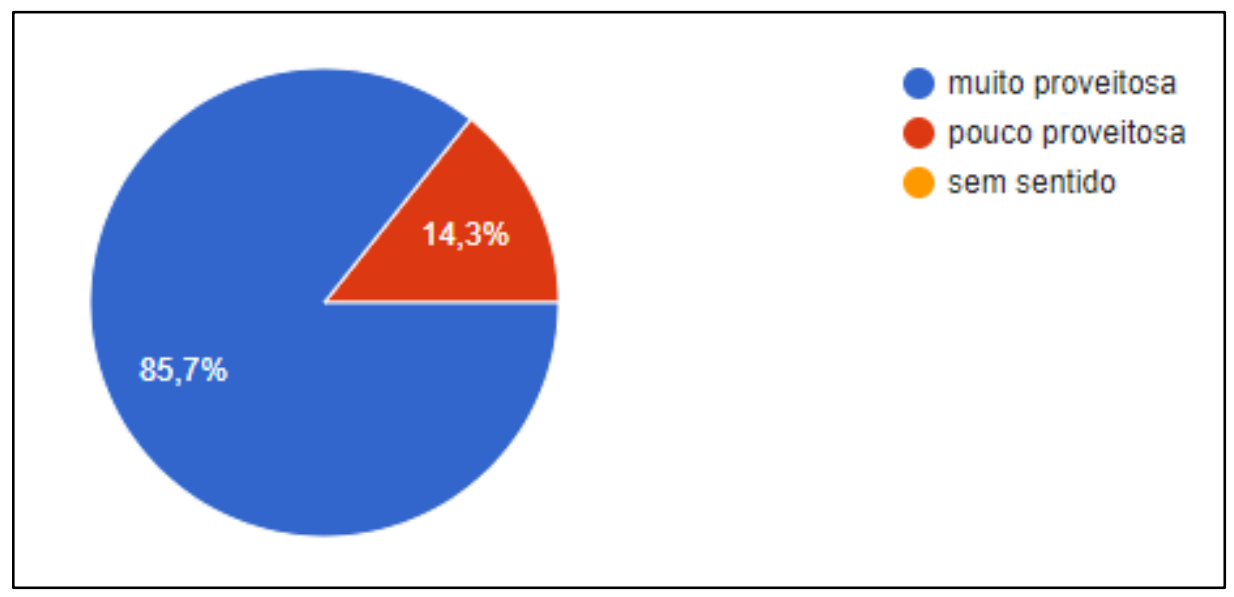

Fonte: produção dos pesquisadores.

Percebe-se que $85,7 \%$ dos acadêmicos consideraram a atividade muito proveitosa e $14,3 \%$ pouco proveitosa.

Raimundo destaca a necessidade de criar ambientes para que a experimentação tenha seu lugar no ambiente escolar, "dando oportunidade para que o aluno seja protagonista da sua história, dos seus processos, liderando sua própria aprendizagem, resultando no desenvolvimento do estudante como cidadão, como ser humano e indivíduo socialmente envolvido". (RAIMUNDO, 2020).

Sobre a significação dos conhecimentos trabalhados pela atividade $100 \%$ dos acadêmicos consideraram que fizeram sentido.

Piaget (1972) destaca que o contato com um objeto externo no processo de aprendizagem funciona como um estímulo promovendo uma estruturação cognitiva que resulta na assimilação do conteúdo estudado.

Utilizar diferentes métodos de ensino faz com que ocorra motivação dos acadêmicos por parte do processo de ensino proposto. Os espaços físicos e temporais da sala de aula podem tornar-se limitadores enquanto espaços teórico-práticos permitem o 
desenvolvimento de competências dos alunos, imprescindíveis para o ambiente de trabalho.

Quando questionados sobre se a metodologia utilizada ajudou na construção dos conhecimentos, $42,9 \%$ respondeu que muito e $57,1 \%$ respondeu que mais ou menos.

A Figura 2 demonstra, as competências que os acadêmicos responderam que acreditam terem desenvolvido durante a atividade dentre as quais foram listadas: engajamento, criatividade, iniciativa, pensamento crítico, flexibilidade diante do desafio, capacidade de inventividade, relacionamento interpessoal, capacidade de estabelecer relações com o real e o simbólico, capacidade de lidar com as diferenças de pensamento, ideias, capacidade de resolução de conflitos e dilemas transversais. Os pontos destacados no gráfico representam o número de vezes que cada sentença aparece nas repostas obtidas através do questionário aplicado aos entrevistados.

Figura 02 - desenvolvimento de competências

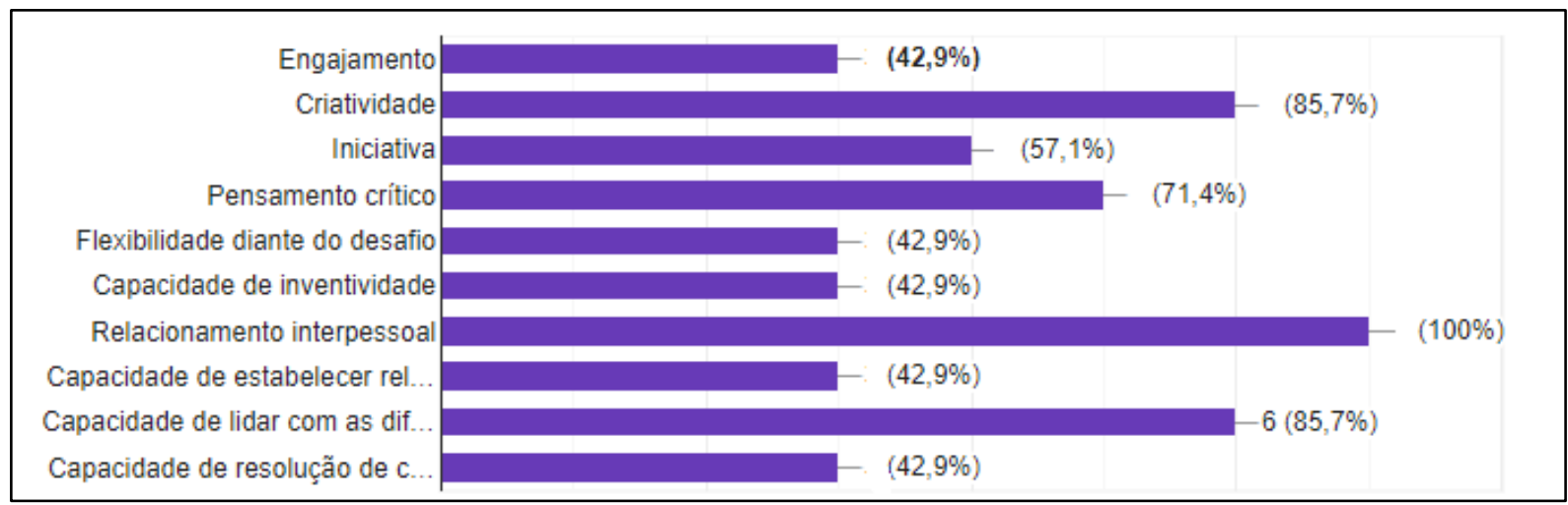

Fonte: produção dos pesquisadores.

Os resultados vem ao encontro do posicionamento que Raimundo, que desta que:

A abordagem do hackathon Educacional potencializa inúmeras habilidades que levam às mais diversas competências, destacando-se, especialmente, autonomia, cooperação, cultura digital e pensamento crítico, científico e criativo. Assim, oferecer aos alunos momentos e maratonas de criatividade e inovação é essencial para se fazer uma escola mais inovadora e conectada às necessidades contemporâneas, tanto no sentido coletivo quanto individual, dando-lhes novas formas de estar em contato com o conhecimento entre seus pares, respeitando as variadas formas de aprender. (RAIMUNDO, 2020, s/p). 
Os acadêmicos precisam ver significado no que estão aprendendo, assimilando as informações, construindo conceitos e atuando em momentos alternativos de aprendizagem que contribuam na função formativa. Para isso, é necessário saber o que transmitir, a quem transmitir e como transmitir.

Já o papel do professor não é professor apenas dominar um determinado conhecimento, mas compreendê-lo em todas as suas dimensões. O processo de ensinoaprendizagem pode ganhar assim, com o uso de metodologias ativas, um dinamismo, inovação e poder de comunicação inusitados desafiando o aluno a raciocinar, usando o que ele já sabe (concepções alternativas), ao mesmo tempo que exige um nível de abstração maior e proporciona a interação com os colegas em sala de aula despertando o prazer pela aprendizagem.

Ainda, quando questionados sobre seu papel na atividade, os resultados estão demostrados na Figura 3.

Figura 03 - papel do acadêmico na atividade

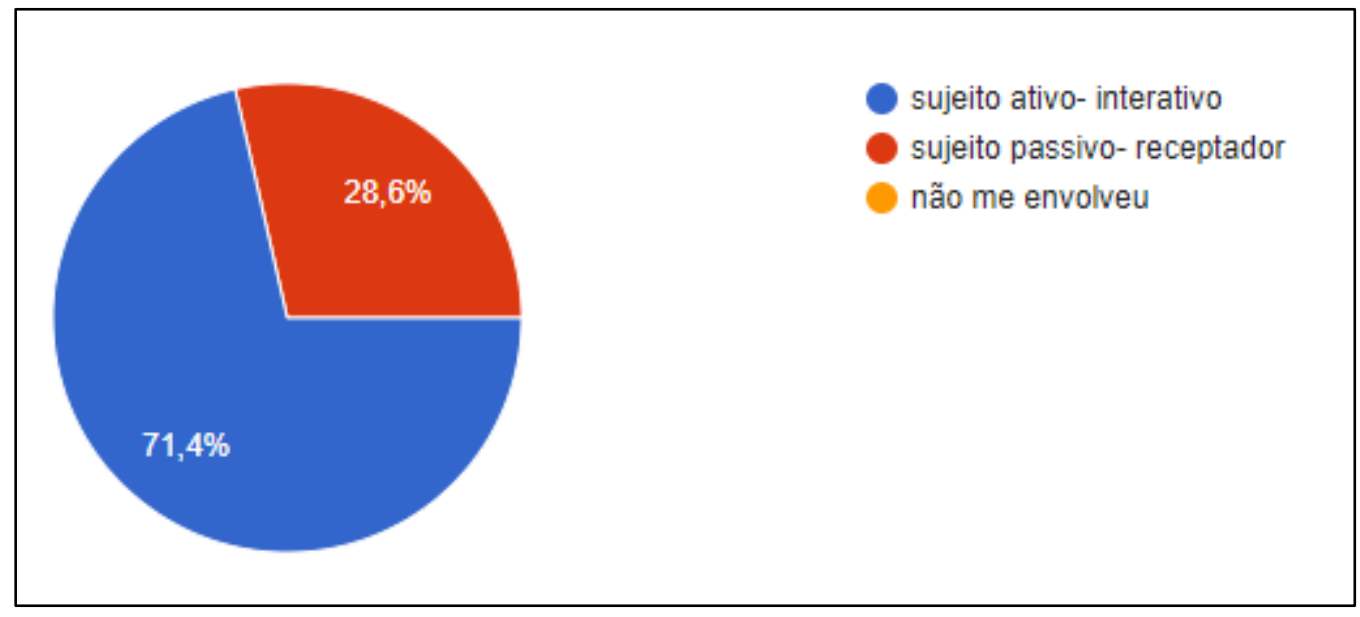

Fonte: produção dos pesquisadores.

Fleck (2010) lembra sobre a importância de questionamentos sobre o processo ensino-aprendizagem que apenas transmite aos alunos definições que são tidas como prontas, acabadas, inquestionáveis.

A própria experiência no ambiente escolar mostra que aulas dialogadas e aspectos ligados a afetividade e motivação dos estudantes são aspectos importantes no processo de ensino e aprendizagem. 
Na avaliação do processo algumas das respostas podem ser visualizadas na Figura 04:

Figura 04 - avaliação geral do processo

A experiência proporcionada pelo Hackathon Health foi imensamente gratificante em nossa trajetória acadêmica. A atividade foi proposta visando o desenvolvimento de habilidades importantes a formação profissional do enfermeiro, inovador, gestor, líder e protagonista em saúde, características que alicerçam o futuro profissional que seremos. Fomos desafiados a atender demandas reais de problemas de saúde existentes na nossa comunidade e resolvê-lo conforme nossas habilidades ja desenvolvidas. Durante o processo de criação passamos por inúmeras adversidades e imprevistos de diversas formas e momentos tendo que aprender a solucionar problemas e a trabalhar em grupo para a conclusão da atividade. Ao fim do Hackathon realizamos a apresentação da nossa proposta e fomos agraciados com o primeiro lugar. A gratificação, o sentimento de dever cumprido e de estar a cada dia um passo mais próximo de nossa formação acadêmica são momentos que fazem valer a pena e que levaremos conosco, em uma atividade que toda nossa turma sem exceções foi vencedora. Acredito que falo por todos ao agradecer a honra de participar do projeto junto a mentes inovadores e brilhantes que nos auxiliaram em todo o processo.

A atividade Hackathon teve como objetivo a criação de propostas inovadoras para aplicação na área da saúde. Tivemos que pensar "fora da caixa", visando solucionar um problema real de maneira viável com a utilização de ferramentas inovadoras e de fácil acesso. Diante disso, foi necessário a atuação coletiva, a busca de bases teóricas e tomada de decisões que proporcionaram a sairmos da nossa zona de conforto. Duas noites de muito aprendizado que certamente contribuíram para nosso crescimento acadêmico e perfil holístico, demonstrando que a área da inovação está alinhada com a enfermagem pois ambas se fazem fundamentais no cenário em que vivenciamos.

Vínhamos estudando e aprendendo ao decorrer da disciplina de empreendedorismo como a enfermagem se insere empreendedora. Na sexta-feira do dia 3 de julho, apresentamos o projeto que cada grupo desenvolveu por meio da atividade denominada Hackathon. É um mundo completamente novo, talvez não estamos acostumados com essa visão da enfermagem que vai além do cuidado. É desafiador!

A atividade foi incrível! Mesmo que de forma on-line conseguimos absorver muito aprendizado dos moderadores de várias áreas que estavam presentes, foi uma troca de 
experiências. O diferencial é aprendermos por meio desses desafios. Agradeço aos professores que estão nos mostrando todos os caminhos novos que a enfermagem pode ocupar e por nos ajudar a desenvolver a criatividade!

Nos dias 25/06 e 02/07 participei pela primeira vez do Hackathon, que foi proporcionado para nós Acadêmicos de Enfermagem do $5^{\circ}$ semestre, pela FEMA em conjunto com a IATI. Sou grata por ter participado deste evento e ainda mais por ter uma equipe fantástica comigo. Fomos desafiados a pensar soluções inovadoras para uma problemática que está presente em nossa comunidade. Foram duas noites desafiadoras e com muito aprendizado. Também houve uma semana para nos planejar, colocar a criatividade em prática e desenvolver uma solução. Uma experiência incrível que me fez crescer como pessoa e futura profissional da área da saúde.

O trabalho Hackathon, foi de grande aprendizado. No início quando foi imposto esse trabalho ficamos apreensivos e com medo pois gerou um desconforto por estarmos saindo da zona de conforto. Com o passar dos dias e conversa com professores, o trabalho foi se tornando cada vez mais atrativo, e enquanto realizava a atividade percebi que para ser um profissional inovador é preciso ter alguns diferencias, pois o mercado de trabalho está cada vez mais rigoroso e concorrido buscando profissionais atualizados onde as tecnologias e inovações se inserem no nosso dia a dia. Após realizar esse trabalho que foi considerado um desafio tive mais clareza que devemos sempre buscar conhecimentos para podermos trabalhar e enfrentar mudanças e incertezas sendo um bom profissional do futuro.

Fonte: produção dos pesquisadores.

O estudante se relaciona melhor com a disciplina quando sentir que existe uma relação com sua vida cotidiana, quando for ouvido pelo professor e sentir que este valoriza e incentiva suas ideias. Assim, o Hackathon, uma maratona que proporciona uma programação exploratória e investigativa, representa a possibilidade de aprendizado por meio de problemas reais que emeregiram do mundo do trabalho e a partir de uma necessidade do serviço de saúde, permitindo ainda que os acadêmicos avaliem se as soluções apresentadas são aplicáveis à sua realidade. Além disso, há a possibilidade de aprender com a metodologia e levar o mindsed para outros problemas encontrar a nível local e regional. 


\section{CONSIDERAÇÕES FINAIS}

Diferentemente do século XIX onde existia separação entre os alunos que iam para as fábricas e o que buscariam carreiras mais promissoras, vivemos em um mundo em que todos precisam manter a constante busca pelo conhecimento e desenvolver seu potencial máximo.

Para atender as necessidades da chamada sociedade do conhecimento é necessário desenvolver modalidades de ensino e aprendizagem personalizadas (CAVALHEIRI ET AL., 2013), e fugir de um sistema de ensino onde as crianças ainda são classificadas por faixa etária. Segundo Robinson (2010) os alunos tem habilidades e formas de aprendizado diferente. Conformidade e maior crescimento são só objetivos dos testes e currículos padronizados.

É preciso pensar de outra forma sobre a capacidade humana superando velhos conceitos. Precisa-se reconhecer que o aprendizado acontece em grupos e que colaboração é a chave do crescimento. Ao avaliarmos pessoas isoladamente forma-se uma disjunção entre elas e o ambiente natural de aprendizado (ROBINSON, 2010). É preciso uma mudança de paradigma.

Nesse contexto, para Robinson (2010) com o crescimento acelerado das tecnologias, o papel do professor mediador, criativo e inovador é fundamental no processo dinâmico da aprendizagem, pois o domínio de uma profissão não exclui o seu aperfeiçoamento. Cavalheiri et al. (2013) afirmam que,

Apesar de não ser a tecnologia que realiza ensino e aprendizagem, mas sim cursos, alunos, professores, famílias, escolas e universidades, é impossível vislumbrarmos uma educação mais personalizada em larga escala sem o uso da tecnologia: ela está presente no dia-a-dia dos alunos, é flexível, atende preferências, está amplamente disponível, e permite observar o que não é visível na cultura presencial e do papel. (CAVALHEIRI ET AL., 2013, p. 35-36)

Além de permitir uma mudança de abordagem no conteúdo a ser estudado, o uso de recursos tecnológicos permite aos educadores acompanhar o desempenho e progresso de seus alunos, possibilitando ainda, outras formas de superar as dificuldades de aprendizado. "Por fim, ela também permite diferentes tipos de interação entre pessoas 
que estão distantes, sejam elas colegas, pessoas que partilham os mesmos interesses, professores e comunidade em geral.” (CAVALHEIRI ET AL., 2013, p. 36).

As instituições de ensino devem estimular uma mudança no ambiente escolar, em que o aluno esteja no centro da aprendizagem, fazendo com que estes assumam maiores responsabilidades e estimulando-os para que progridam constantemente e sejam responsáveis por suas decisões. Segundo Cavalheiri et al. (2013),

O papel da tecnologia na educação personalizada é permitir que os alunos avancem cada vez mais, e sejam cada vez mais desafiados, que professores compreendam suas necessidades, curiosidades e dificuldades e os ajudem, e que os alunos, professores, família e comunidade em geral interajam com cada vez mais intensidade. (CAVALHEIRI ET AL., 2013, p. 37)

Na aprendizagem personalizada é importante que o professor trabalhe em equipe, o ambiente de aprendizagem seja interativo, flexível e em constante avaliação. Cada aluno aprende a seu tempo e o professor deve ficar atento as habilidades e competências de cada um, chamando-os a participar e interagir com os demais. Oferecer conteúdo em diferentes formatos, utilizando textos, animações, áudio e vídeo faz parte do atual processo de ensino. Conforme Cavalheiri et al. (2013),

Para a educação se tornar efetivamente personalizada, precisamos, acima de tudo, que professores, alunos e administradores escolares que acreditem nela e desenvolvam estratégias para colocá-la em prática. Professores e gestores devem buscar conhecer melhor os alunos, oferecer mais possibilidades de êxito em qualquer nível e desenvolver estratégias variadas de avaliação da aprendizagem. Os alunos, por sua vez, devem saber que podem se desenvolver sempre mais, e se responsabilizar por isso. (CAVALHEIRI ET AL., 2013, p. 48)

No entanto, para um bom uso das metodologias ativas é preciso clareza dos objetivos que se deseja alcançar com cada método. A aprendizagem ativa é um recurso poderoso quando utilizado corretamente buscando agregar valor ao processo de ensino e aprendizagem. 


\section{REFERÊNCIAS}

ALVES, Lynn Rosalina G. Game Over: Jogos eletrônicos e violência. São Paulo: Futura, 2005.

CAVILHEIRI, Alceu; ENGERROFF, Sérgio N.; SILVA, Jolair da Costa. As Novas Tecnologias e os Desafios para uma Educação Humanizadora. Santa Maria: Biblos, 2013.

DEWEY, John. Democracia e Educação. São Paulo: Ática, 2007.

FLECK, Ludwik. Gênese e desenvolvimento de um fato científico: introdução à doutrina do estilo de pensamento e do coletivo de pensamento. Belo Horizonte: Fabrefactum, 2010.

FOUREZ. Crise no Ensino de Ciências? Investigações em Ensino de Ciências. Instituto de Física - UFRGS, v.8, n.2, 2003.

FREIRE, P. Pedagogia do Oprimido. 17 ed. Rio de Janeiro: Paz e Terra, 1987.

GOODSON, Ivor F. Currículo: Teoria e história. Petrópolis, RJ: Vozes, 1999.

OLIVEIRA, C. A. A., \& Alves, L. L. (2019). Hackathon como instrumento de inovação aberta. Disponível em:

https://www.fdc.org.br/conhecimento/publicacoes/artigos-revista-dom-34056

PIAGET, Jean. Fazer e Compreender. São Paulo: Edições Melhoramento,1972.

Raimundo, S. G. Hackathon como modelo de aprendizagem ativa, autônoma e criativa para escolas. Disponível em <https://foreducationedtech.com.br/blog/modelohackathon-para-escolas/>.Aceso em 22 jun. 2021, 2020.

ROBINSON, Ken. O Elemento. Lisboa: Porto Editora, 2010.

STRIADER, Roseline Beatriz, et al. A Abordagem de Temas no Ensino Médio: Compreensões de Professores de Física. Disponível em < http://www.portal.fae.ufmg.br/ seer/index.php/ensaio/article/view/461/968> Acesso em: 26 jun. 2021, 2008.

VEEN, Wim; VRAKKING, Ben. Homo Zappiens: educando na era digital. Porto Alegre: Artmed, 2009. 